\title{
Sarbanes-Oxley Act Early Effect: An Empirical Research Using Auditor Change Prediction Data Mining Approaches
}

\author{
Wikil Kwak \\ University of Nebraska at Omaha, USA
}

\begin{abstract}
This study proposes using multiple criteria quadratic programming (MCQP) and other data mining approaches to predict auditor changes with early adopters of the Sarbanes-Oxley Act (SOX). It compares 2003-2004 U.S. firm data with data from 2005-2006 to measure the SOX effect on firms that voluntarily adopted this new regulation nearly (other than the size of the business). The results of the MCQP and other data mining approaches in this auditor change prediction study show that the MCQP method performs marginally better than other data mining approaches using financial and other data to predict auditor changes. In addition, the early SOX effect is not significant empirically using the auditor change prediction model of comparing the prediction rates of early adopters vs. those of later adopters.
\end{abstract}

Keywords: Sarbanes-Oxley Act (SOX), data mining, multiple criteria quadratic programming (MCQP)

\section{Introduction}

The Sarbanes-Oxley Act (SOX) of 2002 was introduced to improve corporate disclosures and the financial accounting information environment, but the costs of implementing the Act may overshadow the benefits of SOX. SOX requires that management and auditors report that there are no material weaknesses in their internal control systems (Boland, Bronson, \& Hoget, 2015). Because of the estimated higher costs of SOX Section 302 and 404 implementations, the Security and Exchange Commission (SEC) and the Public Company Accounting Oversight Board (PCAOB) proposed a compromised solution by extending the 404 compliance deadline for both small and foreign private firms. Recently, Lee, Strong, and Zhu (2014) found that a regulation such as SOX improved the corporate information environment and, as a consequence, reduced security mispricing. In addition, Rezee, R. Espahbodi, P. Espahbodi, and H. Espahbodi (2012) discovered that the Dodd-Frank Act of 2010 improved SOX 404 compliance and made it more cost-effective and efficient. Therefore, it is interesting to compare and contrast the effect of the early stages of SOX for early adopters vs. later adopters of SOX, disregarding firm size. In this paper, early adopters are defined as the firms that voluntarily implemented SOX before the dead line. The time period from 2003-2004 is designated as the early adoption period and 2005-2006 as the later adoption period. Previous empirical research showed mixed results for new regulation effects such as SOX (Lee et al., 2014). Recently, Boland et al. (2015) found empirically that misstatements in financial reporting decreased with the later SOX filers. This issue will be important for auditors preparing audit planning procedures if they can predict that some firms may need more rigorous auditing and assessment of their internal control system and may need to charge higher audit fees (Lenard, Petruska, Alam, \& Yu, 2011). Investors may demand more reliable financial information for their portfolio after SOX.

Wikil Kwak, professor, Department of Accounting, College of Business Administration, University of Nebraska at Omaha. Email:wkwak@unomaha.edu. 
Computing has become more cost-effective with current information technology. Data mining has been applied for numerous business applications in accounting, finance, and marketing such as bankruptcy prediction, fraud detection, detection of tax evasion, credit card defaults, and as an audit-planning tool for assessing internal control weaknesses of firms that is required by SOX.

The purpose of this study is to propose a multiple criteria quadratic programming (MCQP) and other data mining approaches for the prediction of auditing changes including internal control weakness and other characteristics of firms who adopted the SOX earlier vs. later.

This paper is organized as follows: The next section presents the background relevant to this study. The third section presents a MCQP data mining model. The fourth section describes data collection procedures and reports empirical results using other data mining tools. The last section concludes with a summary of findings and future research avenues.

\section{Background}

Gao (2011) observed that foreign firms' equity issues were increasing after SOX. This is indirect evidence showing the positive economic impact of SOX in the U.S. capital market. Harp, Myring, and Shortridge (2014) also found that SOX and other regulations improved the quality of financial information for analysts and investors.

The SEC requires that large firms with market capitalization of at least $\$ 75$ million and to which other Exchange Act rules apply must comply with the SOX 404 rules regarding internal control weakness reports beginning with the fiscal year ending after November 15, 2004 (Ebrahim, 2010). However, the SEC loosened the rule and later proposed even extending the 404 compliance deadline for both small firms and foreign private firms to fiscal years ending on or after December 15, 2007. Therefore, this research focuses on early adopters of the SOX excluding small and foreign private firms and uses MCQP and other data mining approaches with the auditor change prediction model.

De Korvin, Shipley, and Omer (2004) proposed a realistic approach to assess risks of internal control using the fuzzy set theory. However, their method requires managers to develop questionnaires regarding their internal control systems and this could be expensive and time-consuming.

Senteney, Chen, and Gupta (2006) used the logistic regression model to predict firm bankruptcy and found that financial ratios relevant to predict firm distress may also be a useful tool to predict the internal control weaknesses in a firm. Ohlson (1980) used a logit model that does not require normal distribution of sample firms to predict bankruptcy by using nine financial variables. A similar approach to predict financial distress could be used, but the focus here will be internal control weakness factors and factors relevant to internal control weaknesses need to be included. Ge and McVay (2005) used business complexity, firm experience, size, profitability, and auditors to assess the firm characteristics of internal control weaknesses. These variables are included in this study also. J. Krishnan, J. Krishnan, and Stephens (1996) recognized that auditors are more likely to issue qualified audit opinions to firms that switch auditors.

Lenard et al. (2011) discovered that some components of corporate governance such as better governance and big $\mathrm{N}$ audit firms are related to audit fees and these factors are related to predicting fraud litigation after SOX. Kao, Li, and Zhang (2013) also found that Big 4 auditors handled client pressure well even before the SOX Act. Similarly, Ettredge, Scholz, and Li (2007) observed that audit clients paying higher fees were more likely to dismiss their auditors after the SOX Act. Lary and Taylor (2012) found that audit committee 
independence and competence was related to higher quality of internal control systems for a firm. Therefore, these relevant variables found in the database are also included in this study.

Sung, Chang, and Lee (1999) used the decision tree approach to develop bankruptcy prediction models for normal and crisis economic conditions and found that different financial ratios are significant in different economic conditions. The decision tree approach was also used for comparison purposes.

\section{Models of MCQP Classification}

The data mining algorithms can be implemented by several methods of mathematical techniques. For example, prediction methods can be constructed by decision tree, statistics, and neural networks as previous studies have used.

Shi, Peng, Kou, and Chen (2005) developed a general concept of data classification by using MCQP. The basic concept of the formulation can be shown as follows.

Given a set of $k$ variables about the SOX early adopters or non-early (later) adopters, sample firms in database $\boldsymbol{a}=\left(a_{1}, \ldots, a_{k}\right)$, let $\boldsymbol{A}_{i}=\left(A_{i 1}, \ldots, A_{i k}\right) \boldsymbol{R}^{k}$ be the sample observations of data for the variables, where $i=1, \ldots, n$ and $n$ is the sample size. The goal is to determine the coefficients of the variables, denoted by $\boldsymbol{X}=\left(x_{1}, \ldots, x_{k}\right)^{T}$, and a boundary value of $b$ to separate the two classes: $E$ (early adopter) and $N$ (non-early adopter). In this paper, early adopter means the firms that adopted SOX voluntarily during 2003-2004 and non-early adopter means the firms that adopted SOX during 2005-2006; then:

$$
\boldsymbol{A}_{i} \boldsymbol{X} \leq b, \boldsymbol{A}_{i} \in E \text { (early adopter) and } \boldsymbol{A}_{i} \boldsymbol{X}>b, \boldsymbol{A}_{i} \in N \text { (non-early adopter) }
$$

Consider now two kinds of measurements for better separation of the early adopters of SOX firms and non-early adopters of SOX firms. Let $\alpha_{i}$ be the overlapping degree with respect to $\boldsymbol{A}_{\boldsymbol{i}}$, and let $\beta_{i}$ be the distance from $\boldsymbol{A}_{i}$ to its adjusted boundary. In addition, $\alpha$ is defined to be the maximum overlapping of two-class boundaries for all cases $\boldsymbol{A}_{i}\left(\alpha_{i}<\alpha\right)$ and $\beta$ to be the minimum distance for all cases $\boldsymbol{A}_{i}$ from its adjusted boundary $\left(\beta_{i}>\beta\right)$. The (star) represents $\boldsymbol{A}_{i}$ of non-early adopters of SOX and the (dot) represents $\boldsymbol{A}_{i}$ of early adopters of SOX firms. Figure 1 shows that the goal is to minimize the sum of $\alpha_{i}$ and maximize the sum of $\beta_{i}$ simultaneously.

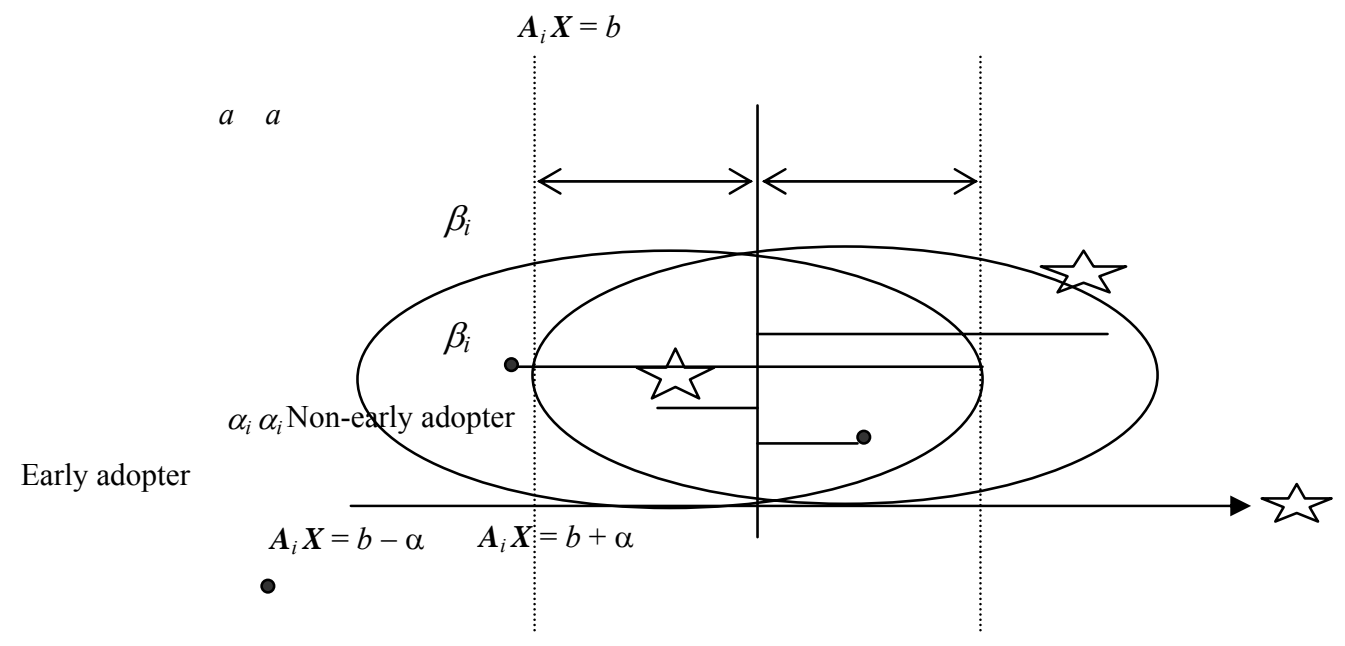

Figure 1. Two-group classification model. 
Then, a general nonlinear function $\mathrm{f}(\alpha)$ can be used to describe the totality of overlapping $\alpha_{i}$ while another nonlinear function $\mathrm{g}(\beta)$ shows the aggregation of the distance $\beta_{i}$. The final rates depend on simultaneously minimizing $\mathrm{f}(\alpha)$ and maximizing $\mathrm{g}(\beta)$ as:

(General Model) Minimize $\mathrm{f}(\alpha)$ and Maximize $\mathrm{g}(\beta)$

Subject to:

$$
\begin{aligned}
& A_{i} \boldsymbol{X}-\alpha_{i}+\beta_{i}-b=0, A_{i} \in E \\
& A_{i} \boldsymbol{X}+\alpha_{i}-\beta_{i}-b=0, A_{i} \in N
\end{aligned}
$$

where $A_{i}$ is given, $X$ and $b$ are unrestricted, and $\alpha=\left(\alpha_{1}, \ldots, \alpha_{r i}\right)^{\Gamma}, \beta=\left(\beta_{1}, \ldots, \beta_{r i}\right)^{\Gamma} ; \alpha_{i}, \beta_{i} \geq 0, i=1, \ldots, n$.

In order to utilize the computational power of nonlinear software packages to classify the data, the general model is modified using norm $\rho, \rho \geq 1$. Given weights $\boldsymbol{W}_{\alpha}$ and $\boldsymbol{W}_{\beta}$, let $\mathrm{f}(\alpha)=|\alpha|^{\rho}$ and $\mathrm{g}(\beta)=|\beta|^{\rho}$.

The two-criteria programming model converted into one criterion classification model as:

Model (1) Minimize $W_{\alpha}|\alpha|^{\rho}-W_{\beta} \mid \beta^{\rho}$

Subject to:

$$
\begin{aligned}
& A_{i} X-\alpha_{i}-\beta_{i}-b=0, A_{i} \in E \\
& A_{i} X+\alpha_{i}-\beta_{i}-b=0, A_{i} \in N
\end{aligned}
$$

where $\boldsymbol{A}_{i}$ is given, $\boldsymbol{X}$ and $b$ are unrestricted, $\alpha=\left(\alpha_{1}, \ldots, \alpha_{r i}\right)^{\Gamma}, \beta=\left(\beta_{1}, \ldots, \beta_{r i}\right)^{\Gamma} ; \alpha_{i}, \beta_{i} \geq 0, i=1, \ldots, n$ (Shi et al., 2005, p. 591).

Based on Model (1), nonlinear classification models with norm $\rho(\rho=1$ or $\infty)$ can be theoretically defined. For this study, the goal was to formulate a quadratic programming model. Let $\rho=2$, then $|\alpha|^{2}={ }_{i=1}^{n} \alpha_{i}^{2}$ and $|\beta|^{2}={ }_{i=1}^{n} \beta_{i}^{2}$.

Model (1) now becomes Model (2):

(Model 2) Minimize $W_{\alpha}{ }_{i=1}^{n} \alpha_{i}^{2}-W_{\beta}{ }_{i=1} \beta_{i}^{2}$,

Subject to:

$$
\begin{aligned}
& A_{i} \boldsymbol{X}-\alpha_{i}-\beta_{i}-b=0, A_{i} \in E \\
& A_{i} \boldsymbol{X}+\alpha_{i}-\beta_{i}-b=0, A_{i} \in N
\end{aligned}
$$

where $A_{i}$ is given, $X$ and $b$ are unrestricted, and $\alpha=\left(\alpha_{1}, \ldots, \alpha_{r i}\right)^{\Gamma}, \beta=\left(\beta_{1}, \ldots, \beta_{r i}\right)^{\Gamma} ; \alpha_{i}, \beta_{i} \geq 0, i=1, \ldots, n$.

The above MCQP model can be solved using LINGO 8.0 to solve Model (2).

\section{Data Collection and Research Design}

In this paper, 157 auditor change firms among early SOX adopters were collected using DirectEdgar (2009) for the years 2003 and 2004, and 306 matching control firms by size and two-digit industry code within the same time frame. The control firms almost doubled the number of change firms. This paper wanted to replicate the real world auditor change situation and more than double the size of matching control firms as financial and other data from the database might be lost. From 2005 to 2006, 112 auditor change firms and 270 matching control firms were found. The financial sample is composed of firms with their financial and other data available from 10-K filings using DirectEdgar (2009). 
Table 1

Descriptive Statistics

\begin{tabular}{|c|c|c|c|c|c|}
\hline \multicolumn{6}{|c|}{ Panel A: SOX early adopt firms during years of 2003-2004 with auditor changes ( $n=157)$} \\
\hline Variable & Mean & Std. dev. & & \multicolumn{2}{|c|}{ Max. } \\
\hline Qualified $O p$ & 0.0955 & \multicolumn{2}{|c|}{0.2949} & 0 & 1 \\
\hline$T A$ & $6,831.818$ & \multicolumn{2}{|c|}{$22,420.83$} & 0.019 & 185,094 \\
\hline Dividend & 62.1682 & \multicolumn{2}{|c|}{193.4417} & 0 & 1150 \\
\hline$E B I T / T A$ & -0.3599 & \multicolumn{2}{|c|}{1.6232} & -14.5753 & 0.3008 \\
\hline$F U / T L$ & 0.1017 & \multicolumn{2}{|c|}{0.4622} & -2.2095 & 3.1759 \\
\hline INTWO & 0.4140 & \multicolumn{2}{|c|}{0.4641} & 0 & 1 \\
\hline NI/TA & -0.5773 & \multicolumn{2}{|c|}{2.0028} & -15.0731 & 0.3004 \\
\hline Size & 5.9944 & & 174 & -3.9633 & 12.1286 \\
\hline$R E / T A$ & -3.7205 & & & -163.429 & 0.6388 \\
\hline$T L / T A$ & 1.4851 & & 174 & 0.0872 & 29.4355 \\
\hline ONEG & 0.1720 & & 786 & 0 & 1 \\
\hline Sales/TA & 1.0423 & & 704 & 0 & 7.0519 \\
\hline$M K V / T D$ & 9.7562 & & 703 & 0.0544 & 330.3171 \\
\hline Growth & 0.0748 & & 842 & -3.5130 & 2.2767 \\
\hline CHIN & 0.0758 & & 701 & -1 & 1 \\
\hline Audit Fee & $1,881,233$ & $3,896,542$ & & 12,500 & $32,800,000$ \\
\hline Fee Ratio & 0.7493 & & 830 & 0.2214 & 1 \\
\hline$C L / C A$ & 1.7911 & & 971 & 0.0625 & 49.75 \\
\hline$W C / T A$ & -0.3589 & & 481 & -20.5263 & 0.7055 \\
\hline Big 4 & 0.8471 & & 610 & -20.5263 & 0.7055 \\
\hline & el B: SOX early adopt & t firms during years & f2003-2004 v & with non-auditor changes $(n$ & $=306)$ \\
\hline Variable & Mean & Std. dev. & Min. & Max. & $t$-test ${ }^{(1)}$ \\
\hline Qualified $O p$ & 0.0556 & 0.2294 & 0 & 1 & 0.7803 \\
\hline$T A$ & $5,239.628$ & $21,406.67$ & 0.098 & $224,564.2$ & $106.0811^{* * *}$ \\
\hline Dividend & 49.9713 & 195.1353 & 0 & $1,913.484$ & $8.9246^{* * *}$ \\
\hline$E B I T / T A$ & -0.0390 & 0.9710 & -13.7857 & 0.3450 & $-2.7616^{* * *}$ \\
\hline$F U / T L$ & 0.2117 & 0.4807 & -2.7890 & 2.5424 & -1.6379 \\
\hline INTWO & 0.2549 & 0.4365 & 0 & 1 & $2.3539^{* *}$ \\
\hline$N I / T A$ & -0.1015 & 1.1766 & -17.3651 & 0.3650 & $-3.6944^{* * *}$ \\
\hline Size & 6.6100 & 1.8199 & -2.3228 & 12.3219 & -0.9320 \\
\hline$R E / T A$ & -0.8377 & 4.8585 & -54.398 & 0.7352 & $-8.3277^{* * *}$ \\
\hline$T L / T A$ & 0.7568 & 2.4223 & 0.0692 & 31.8968 & $4.0989^{* * *}$ \\
\hline ONEG & 0.0490 & 0.2163 & 0 & 1 & $2.2028^{* *}$ \\
\hline Sales/TA & 0.9118 & 0.7417 & 0 & 5.2236 & 1.3581 \\
\hline$M K V / T D$ & 3.6833 & 24.8731 & 0.0130 & 432.255 & $10.9842^{* * *}$ \\
\hline Growth & 0.1406 & 0.3067 & -3.2996 & 1.5906 & -1.0306 \\
\hline CHIN & 0.2327 & 0.5336 & -1 & 1 & $-2.1413^{* *}$ \\
\hline Audit Fee & $1,682,538$ & $3,380,007$ & 8,201 & $38,490,700$ & $1,049.713^{* * *}$ \\
\hline Fee Ratio & 0.6923 & 0.2217 & 0.0588 & 1 & 1.3113 \\
\hline$C L / C A$ & 0.8373 & 1.6123 & 0.0449 & 24.2830 & $4.9112^{* * *}$ \\
\hline$W C / T A$ & 0.1103 & 1.3244 & -19.5873 & 0.9263 & $-3.2732^{* * *}$ \\
\hline Big 4 & 0.9575 & 0.2020 & 0 & 1 & $-2.0297^{* *}$ \\
\hline
\end{tabular}


Notes. Variable descriptions: Qualified $O p=1$, if the firm has qualified audit opinion, and 0 if otherwise; $T A=$ Total assets in $000 \mathrm{~s}$; Dividend $=$ Dividend paid out in 000s; EBIT/TA = Earnings before interest and taxes/total assets (Altman (1968) ratio); $F U / T L=$ Funds from operations/total liabilities (Ohlson (1980) ratio); INTWO $=$ If net income $<0$ or lag (net income) $<0$, then $I N T W O=1$; else $I N T W O=0$ (Ohlson (1980) dummy variable); NI/TA = Net income/total assets (Ohlson (1980) ratio); Size $=$ Total assets/gross domestic products; $R E / T A=$ Retained earnings/total assets (Altman (1968) ratio); TL/TA = Total liabilities/total assets (Ohlson (1980) ratio); $O N E G=$ If $T L / T A>1$, then $O N E G=1$; else $O N E G=0$ (Ohlson (1980) dummy variable); Sales/TA = Sales/total assets (Altman (1968) ratio); $M K V / T D=$ Market value of equity/book value of total debt (Altman $(1968)$ ratio $) ;$ Growth $=\left(\right.$ Sales $_{t}-$ Sales $\left._{t-1}\right) /$ Sales $_{t-1} ; C H I N=($ Net income - lag $($ Net income $)) /[$ absolute $($ Net income $)+$ absolute (lag Net income)] (Ohlson (1980) ratio); Audit Fee = Total audit fee; Fee Ratio = Total audit fee divided by total assets; $C L / C A=$ Total current liabilities/total current assets (Ohlson (1980) ratio); WC/TA $=$ Working capital/total assets (Altman (1968) ratio and Ohlson (1980) ratio); and Big $4=$ If the firms auditor is Big 4, then it is 1 , and 0 if otherwise. ${ }^{(1)}: t$-value for testing mean differences between early SOX and non-early SOX adopting firms. ${ }^{*}: p<0.10 ;{ }^{* *}: p<0.05$; and ${ }^{* * *}: p<0.001$.

Altman's (1968) and Altman, Haldeman, and Narayanan's (1977) variables and Ohlson's (1980) variables were utilized for auditor change prediction. Altman used five ratio variables in his study and Ohlson used nine variables in his study. However, with current available data mining tools and computer capabilities, more variables can be handled without difficulty in the model. Relevant variables found from previous internal control weakness studies were also added.

MCQP and other data mining tools were first run using all variables for the 2003-2004 time frame. Then, MCQP and other data mining tools were run again using the 2005-2006 period to compare the prediction accuracy of the auditor change model for early and later or non-early adopters.

Table 1 above shows the descriptive statistics of auditor change and non-auditor change firms for the SOX early adoption period. As we can see in Panel B, all variables between auditor change and non-auditor change firms during the period of 2003-2004 are significantly different except for qualified opinion, size, sales/total assets, growth, and fee ratios. The size variable is not significantly different since the control firms were matched based on size and industry. The qualified opinion, sales/total assets, growth (which is a similar measure to sales/total assets), and fee ratios are not significant as in previous empirical studies such as Krishnan et al. (1996) and Lenard et al. (2011).

Table 2 presents the descriptive statistics of auditor change and non-auditor change firms for the SOX late adoption period. As shown in Panel B, all variables between auditor change and non-auditor change firms during the period of 2005-2006 are significantly different except for the qualified opinion, size, sales/total assets, fee ratios, and Big 4 variables. Compared with Table 1, growth is significant, but the Big 4 variable is not significant. This is an interesting result as it shows that Big 4 audit firms after SOX implementation are less significant as seen in Kao et al.'s (2013) study.

Table 3 reports auditor changes for before and after SOX. This time, qualified opinion is not significant as seen in previous results. EBIT/TA, FU/TL, and INTWO are not significant. This means that earnings, funds from operation, and negative income measures are not much different before or after the SOX auditor change firms. NI/TA, Sales/TA, and Fee Ratio are marginally significant. ONEG, Growth, CHIN, and Big 4 are not significant before or after the SOX auditor change firms. 
Table 2

Descriptive Statistics

\begin{tabular}{|c|c|c|c|c|c|}
\hline \multicolumn{6}{|c|}{ Panel A: SOX adopt firms during years of 2005-2006 with auditor changes $(n=112)$} \\
\hline Variable & Mean & Std. der & & \multicolumn{2}{|c|}{ Max. } \\
\hline Qualified $O p$ & \multicolumn{3}{|c|}{0.2262} & 0 & 1 \\
\hline$T A$ & \multicolumn{3}{|c|}{$14,890.31$} & 0.254 & $102,623.8$ \\
\hline Dividend & \multicolumn{3}{|c|}{439.6847} & 0 & $2,694.827$ \\
\hline$E B I T / T A$ & \multicolumn{3}{|l|}{-0.1693} & -11.1583 & 0.3429 \\
\hline$F U / T L$ & \multicolumn{3}{|l|}{0.0667} & -1.8216 & 1.6161 \\
\hline INTWO & \multicolumn{3}{|l|}{0.3661} & 0 & 1 \\
\hline$N I / T A$ & \multicolumn{3}{|l|}{-0.2917} & -12.7795 & 0.3703 \\
\hline Size & \multicolumn{3}{|l|}{6.4375} & -1.3704 & 11.5388 \\
\hline$R E / T A$ & \multicolumn{3}{|c|}{10.4252} & -60.5758 & 0.7001 \\
\hline$T L / T A$ & \multicolumn{3}{|l|}{0.8292} & 0.0970 & 11.0472 \\
\hline ONEG & \multicolumn{3}{|l|}{0.1071} & 0 & 1 \\
\hline Sales/TA & \multicolumn{3}{|l|}{0.8358} & 0 & 2.9381 \\
\hline$M K V / T D$ & 5.1570 & & 342 & 0.0071 & 173.0567 \\
\hline Growth & 0.0937 & & 302 & -1.2540 & 1.1133 \\
\hline CHIN & 0.0012 & & 373 & -1 & 1 \\
\hline Audit Fee & $2,376,944$ & $3,718,0$ & & 7,500 & $20,225,200$ \\
\hline Fee Ratio & 0.8372 & & 767 & 0.2598 & 1 \\
\hline$C L / C A$ & 0.9280 & & 969 & 0.1063 & 10.1054 \\
\hline$W C / T A$ & 0.0624 & & 869 & -7.1144 & 0.8151 \\
\hline Big 4 & 0.8214 & & 847 & 0 & 1 \\
\hline & Panel B: SOX adopt $\mathrm{f}$ & irms during years & $2005-2006$ & thout auditor changes $(n=2$ & 270) \\
\hline Variable & Mean & Std. dev. & Min. & Max. & $t$-test $^{(1)}$ \\
\hline Qualified $O p$ & 0.0407 & 0.1981 & 0 & 1 & 0.4737 \\
\hline$T A$ & $3,354.206$ & $9,642.855$ & 14.81 & 110,405 & $75.4932^{* * *}$ \\
\hline Dividend & 63.8363 & 273.7665 & 0 & $2,508.7$ & $13.4574^{* * *}$ \\
\hline EBIT/TA & 0.0495 & 0.1784 & -0.6989 & 0.3474 & $-6.5762^{* * *}$ \\
\hline$F U / T L$ & 0.2414 & 0.5846 & -4.1304 & 2.7263 & $-2.9613^{* * *}$ \\
\hline INTWO & 0.2482 & 0.4327 & 0 & 1 & $2.9456^{* * *}$ \\
\hline$N I / T A$ & 0.0027 & 0.1832 & -1.2546 & 0.3137 & $-9.2803^{* * *}$ \\
\hline Size & 6.5956 & 1.6248 & 2.6953 & 11.6119 & -0.5605 \\
\hline$R E / T A$ & -0.2154 & 0.7725 & -4.5966 & 0.7016 & $-29.0161^{* * *}$ \\
\hline$T L / T A$ & 0.5296 & 0.3165 & 0.0804 & 3.0600 & $4.8681^{* * *}$ \\
\hline ONEG & 0.0444 & 0.2065 & 0 & 1 & $2.2673^{* *}$ \\
\hline Sales/TA & 0.8905 & 0.8270 & 0 & 7.2014 & -0.7388 \\
\hline$M K V / T D$ & 2.2703 & 2.5578 & 0.1298 & 19.1075 & $22.0027^{* * *}$ \\
\hline Growth & 0.1657 & 0.2080 & -0.2048 & 1.6096 & $-2.1812^{* *}$ \\
\hline CHIN & 0.1207 & 0.5060 & -1 & 1 & $-1.8968^{*}$ \\
\hline Audit Fee & $1,911,008$ & $2,730,215$ & 0 & $21,100,000$ & $1,250.03^{* * *}$ \\
\hline Fee Ratio & 0.7836 & 0.2092 & 0 & 1 & 0.6421 \\
\hline$C L / C A$ & 0.8137 & 2.2180 & 0.0498 & 35.4268 & 0.9808 \\
\hline$W C / T A$ & 0.2337 & 0.2723 & -0.8836 & 0.9147 & $-5.0249^{* * *}$ \\
\hline Big 4 & 0.8889 & 0.3149 & 0 & 1 & -0.7771 \\
\hline
\end{tabular}


Table 3

Descriptive Statistics

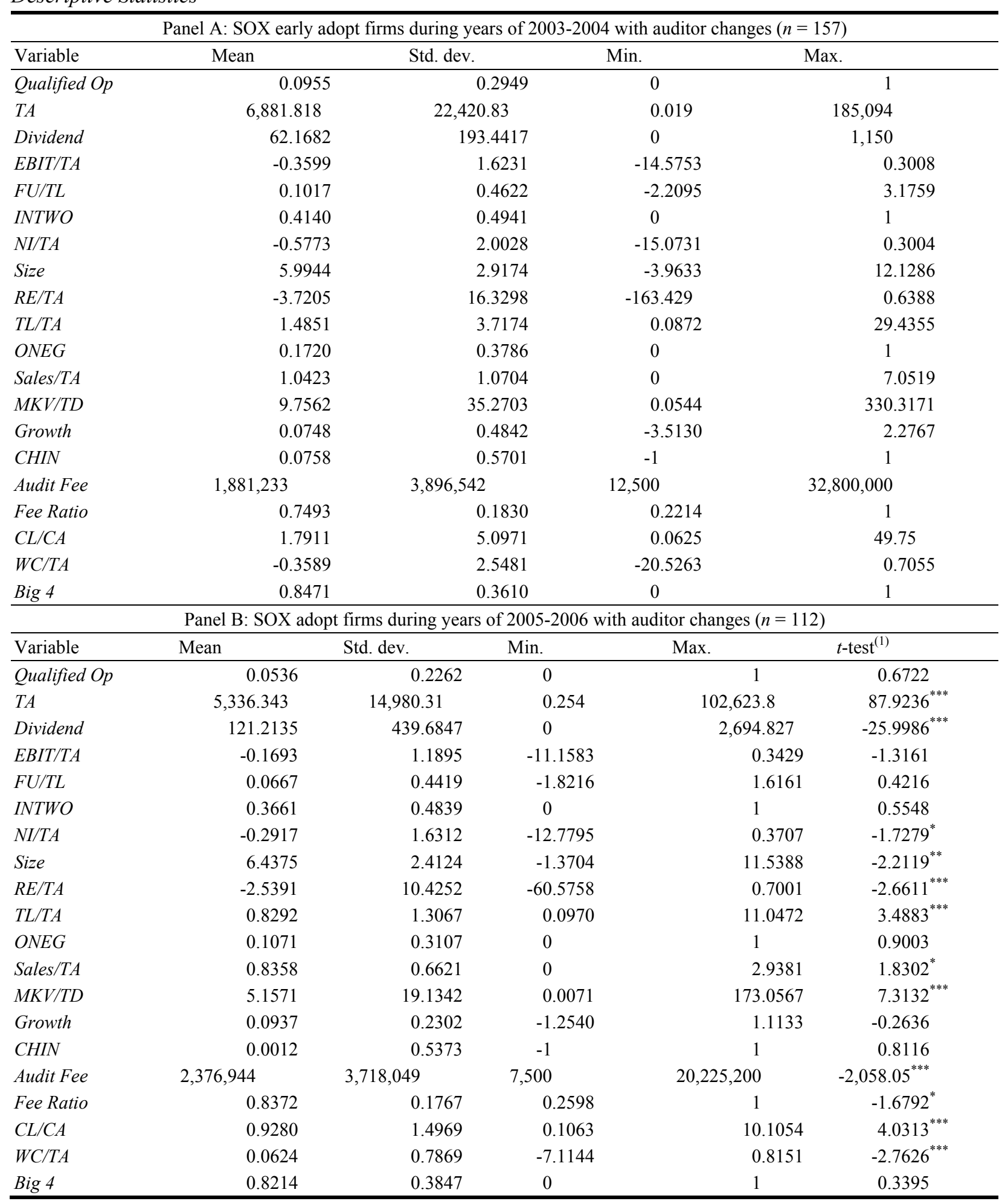


The MCQP, Linear Discriminant Analysis (LDA), Classification Tree, and See5 data mining approaches were applied using financial and other relevant variables to predict auditor changes before and after SOX and their results are reported in Table 4. As a means of validation, the classification results of MCQP (Shi et al., 2005) are compared with two popular classification tools: LDA (SPSS, 2004) and Decision Tree-based See5 (Quinlan, 2004). Five performance criteria are used to evaluate the classification performance: accuracy, KS score, Type I and II errors, and correlation coefficient. Accuracy is one of the most widely used classification performance metrics. Since training results indicate how well the classification model fits the training set and test results reflect the real predicting power of the classification model, Table 4 only summarizes the five metrics for the test sets. The standard 10-fold cross validation process is applied to MCQP and See5. The standard Leave-One-Out validation process is applied to LDA.

LDA shows the lowest prediction rate with the 2003-2004 data. Even though MCQP shows the highest prediction rate $(57.67 \%)$, overall auditor change prediction rates are low. Similar results are shown with the 2005-2006 auditor change data. Comparing before and after SOX auditor change prediction accuracy, it is marginally better for LDA and other models show less improved prediction rates after SOX.

Table 4

Results of Auditor Changes Prediction Before and After SOX

\begin{tabular}{|c|c|c|c|c|c|c|c|}
\hline \multicolumn{8}{|c|}{ Panel A: Prediction accuracy for 2003-2004 auditor change model } \\
\hline \multirow{2}{*}{ Model } & \multicolumn{3}{|c|}{ Classification accuracy } & \multicolumn{2}{|c|}{ Error rate } & \multirow{2}{*}{-KS score } & \multirow{2}{*}{ Corr. coeff. } \\
\hline & Overall & Normal & Bad & Type I & Type II & & \\
\hline LDA & 50.95 & 50.10 & 51.80 & 49.03 & 49.07 & 1.90 & 0.02 \\
\hline Classification Tree & 56.05 & 23.80 & 88.30 & 32.96 & 46.32 & 12.10 & 0.16 \\
\hline See5 & 54.33 & 14.47 & 94.19 & 28.66 & 47.59 & 8.66 & 0.14 \\
\hline MCQP & 57.67 & 55.23 & 60.10 & 41.94 & 42.69 & 15.33 & 0.15 \\
\hline \multicolumn{8}{|c|}{ Panel B: Prediction accuracy for 2005-2006 auditor change model } \\
\hline \multirow{2}{*}{ Model } & \multicolumn{3}{|c|}{ Classification accuracy } & \multicolumn{2}{|c|}{ Error rate } & $V C_{2}$ & \multirow{2}{*}{ Corr. coeff. } \\
\hline & Overall & Normal & Bad & Type I & Type II & KS score & \\
\hline LDA & 57.50 & 51.90 & 63.10 & 41.55 & 43.26 & 15.00 & 0.15 \\
\hline Classification Tree & 58.65 & 52.60 & 64.70 & 40.16 & 42.28 & 17.30 & 0.17 \\
\hline See5 & 56.20 & 46.70 & 65.70 & 42.35 & 44.79 & 12.40 & 0.13 \\
\hline MCQP & 59.97 & 65.37 & 54.56 & 41.01 & 38.83 & 19.93 & 0.20 \\
\hline
\end{tabular}

Table 4 also reports Type I and Type II error rates and other metrics for all models. Usually, the costs of Type I errors outweigh the costs of Type II errors in an auditor change situation, but overall prediction rates are too low so this is not an important issue. From the above results, the MCQP and other data mining approaches show similar or marginally better results before and after the SOX using auditor change prediction models. Therefore, it is not conclusive from the empirical results that the later SOX adopter information environment is better.

\section{Summary and Conclusions}

In this paper, the MCQP and other data mining approaches were used to predict auditor changes using 2003-2004 data compared with changes using 2005-2006 data. The MCQP data mining approach has been applied to credit card portfolio management (Shi et al., 2005). The results of the MCQP approach in this prediction study are promising as this approach performs better than the traditional multiple discriminant 
analysis of LDA or decision tree approaches. However, overall prediction accuracy rates are too low and from these results, it is inconclusive that the information environment after SOX is better. This paper used small sample firms to predict auditor changes. This could be the reason for low prediction rates and missing variables such as audit committee could be included in future research to improve overall prediction rates.

\section{References}

Altman, E. I. (1968). Financial ratios, discriminant analysis and the prediction of corporate bankruptcy. The Journal of Finance, 23(4), 589-609.

Altman, E. I., Haldeman, R. G., \& Narayanan, P. (1977). ZETA analysis: A new model to identify bankruptcy risk of corporations. Journal of Banking and Finance, 1(1), 29-54.

Boland, C. M., Bronson, S. N., \& Hogan, C. E. (2015). Accelerated filing deadlines, internal controls, and financial statement quality: The case of originating misstatements. Accounting Horizons, 29(3), 551-575.

De Korvin, A., Shipley, M. F., \& Omer, K. (2004). Assessing risks due to threats to internal control in a computer-based accounting information system: A pragmatic approach based on fuzzy set theory. Intelligence Systems in Accounting, Finance and Management, 12(2), 139-152.

DirectEdgar. (2009). College of Business Administration, University of Nebraska-Omaha, Omaha, NE 68182, USA.

Ebrahim, A. (2010). Audit fee premium and auditor change: The effect of Sarbanes-Oxley Act. Managerial Auditing Journal, 25(2), 102-121.

Ettredge, M. L., Scholz, S., \& Li, C. (2007). Audit fees and auditor dismissals in the Sarbanes-Oxley era. Accounting Horizons, 21(4), 371-386.

Gao, Y. (2011). The Sarbanes-Oxley Act and the choice of bond market by foreign firms. Journal of Accounting Research, 49(4), 933-968.

Ge, W., \& McVay, S. (2005). The disclosure of material weaknesses in internal control after the Sarbanes-Oxley Act. Accounting Horizons, 19(3), 137-158.

Harp, N., Myring, M., \& Shortridge, R. T. (2014). Do variations in the strength of corporate governance still matter? A comparison of the pre- and post-regulation environment. Journal of Business Ethics, 122(3), 361-373.

Kao, J. L., Li, Y., \& Zhang, W. (2013). Has SOX enhanced non-Big 4 auditors' ability to deal with client pressure? Accounting Perspective, 12(2), 141-164.

Krishnan, J., Krishnan, J., \& Stephens, R. G. (1996). The simultaneous relation between auditor switching and audit opinion: An empirical analysis. Accounting and Business Research, 26(3), 224-236.

Lary, A. M., \& Taylor, D. W. (2012). Governance characteristics and role effectiveness of audit committees. Managerial Auditing Journal, 27(4), 336-354.

Lee, E., Strong, N., \& Zhu, Z. (2014). Did regulation fair disclosure, SOX, and other analyst regulations reduce security mispricing? Journal of Accounting Research, 52(3), 733-774.

Lenard, M. J., Petruska, K. A., Alam, P., \& Yu, B. (2011). Indicators of audit fees and fraud classification: Impact of SOX. Managerial Auditing Journal, 27(5), 500-525.

Ohlson, J. A. (1980). Financial ratios and the probabilistic prediction of bankruptcy. Journal of Accounting Research, 18(1), $109-131$.

Quinlan, J. (2004). See5.0. Retrieved from http://www.rulequest.com/see5-info.html

Rezee, Z., Espahbodi, R., Espahbodi, P., \& Espahbodi, H. (2012). Firm characteristics and stock price reaction to SOX 404 compliance. ABACUS, 48(4), 473-501.

Senteney, D. L., Chen, Y., \& Gupta, A. (2006). Predicting impending bankruptcy from auditor qualified opinions and audit firm changes. Journal of Applied Business Research, 22(1), 41-56.

Shi, Y., Peng, Y., Kou, G., \& Chen, Z. (2005). Classifying credit card accounts for business intelligence and decision making: A multiple-criteria quadratic programming approach. International Journal of Information Technology \& Decision Making, 4(4), 581-599.

SPSS. (2004). Retrieved from http://www.spss.com/training/contents/advStat.htm

Sung, T. K., Chang, N., \& Lee, G. (1999). Dynamics of modeling in data mining: Interpretive approach to bankruptcy prediction. Journal of Management Information Systems, 16(1), 63-85. 